\title{
Sustained Remission of Antineutrophil Cytoplasmic Antibody-Mediated Glomerulonephritis and Nephrotic Syndrome in Mixed Connective Tissue Disease
}

\author{
Konstantin N. Konstantinov ${ }^{\mathrm{a}, \mathrm{f}}$, Alexis A. Harris ${ }^{\mathrm{b}}$, Marc Barry ${ }^{\mathrm{c}}$, \\ Glen H. Murata ${ }^{\mathrm{d}}$, Antonios H. Tzamaloukas ${ }^{\mathrm{e}}$
}

\begin{abstract}
A woman diagnosed with mixed connective tissue disease (MCTD) developed an anti-myeloperoxidase (MPO) antineutrophil cytoplasmic antibody (ANCA) and nephrotic syndrome with normal serum creatinine. Percutaneous kidney biopsy showed pauciimmune glomerulonephritis with superimposed immune complex deposition. After treatment with cyclophophamide and prednisone, proteinuria decreased progressively to a level of $0.4 \mathrm{~g} / \mathrm{g}$ creatinine, ANCA became undetectable, while serum creatinine remained normal seven years after the beginning of treatment. Sustained remission of nephrotic proteinuria with preserved renal function may follow treatment of ANCA-mediated disease developing in patients with MCTD.
\end{abstract}

Keywords: Mixed-connective tissue disease; Antineutrophil cytoplasmic antibodies; Antimyeloperoxidase; Nephrotic syndrome; Pauci-immune glomerulonephritis

\section{Introduction}

Mixed connective tissue disease (MCTD) is an overlap syn-

\footnotetext{
Manuscript accepted for publication May 7, 2013

${ }^{a}$ Division of Rheumatology, University of New Mexico School of Medicine; USA

${ }^{b}$ Nephropath Renal Pathology, Little Rock, Arkansas; USA

'Division of Pathology, University of New Mexico School of Medicine; USA

${ }^{\mathrm{d}}$ Division of General Medicine, University of New Mexico School of Medicine and Raymond G. Murphy VA Medical Center, Albuquerque, New Mexico, USA

${ }^{\mathrm{e}}$ Division of Nephrology, University of New Mexico School of Medicine and Raymond G. Murphy VA Medical Center, Albuquerque, New Mexico, USA

${ }^{\mathrm{f}}$ Corresponding author: Konstantin N. Konstantinov, Division of Rheumatology, Department of Internal Medicine, University of New Mexico School of Medicine, 2111 Lomas NE, 5 ACC Bldg; Mail Stop MSC10-5550, Albuquerque, New Mexico 87131, USA.

Email: kkonstantinov@salud.unm.edu
}

doi: http://dx.doi.org/10.4021/jocmr1391w drome characterized by anti-U1-RNP antibodies and clinical features of systemic lupus erythematosus, scleroderma, and polymyositis [1]. Renal involvement occurs in as high as $40 \%$ in adult [2] and $47 \%$ in pediatric [3] cases. Membranous nephropathy is the most common renal histological picture. Mesangial proliferative glomerulonephritis and membrano-proliferative glomerulonephritis are less frequent $[2,4-6]$.

Infrequent types of renal histology in MCTD include intimal hyperplasia of the renal arterioles associated with scleroderma-type renal crisis [7] and pauci-immune glomerulonephritis, along with other features of vasculitis, following development of positive antineutrophil cytoplasmic antibody -ANCA- [8]. We report a patient with MCTD who developed anti- myeloperoxidase (MPO) ANCA positivity, pauci-immune glomerulonephritis with superimposed immune complex mediated disease, and nephrotic syndrome. Prolonged remission followed treatment directed against ANCA-associated disease.

\section{Case Report}

A 42-year-old woman with past history of hypothyroidism, iron deficiency anemia and nasal sinusitis developed Raynaud's phenomenon, swollen fingers and hands, esophageal dysfunction, acrosclerosis and trigeminal neuropathy. Persistently high anti-U1- RNP titers confirmed the diagnosis of MCTD. Serum rheumatoid factor and antibodies to SS-A were also elevated. Initial serum creatinine was $0.8 \mathrm{mg} / \mathrm{dL}$ and urinalysis revealed trace protein. Her medications included levothyroxine, acetaminophen and lisinopril. She did not use non-steroidal anti-inflammatory drugs. Subsequently, after being clinically stable for years, the patient developed MPO-ANCA positivity and her proteinuria increased progressively to a level of $11 \mathrm{~g} / 24 \mathrm{~h}$. Antibodies against PR3, dsDNA, and SSB were negative. In March 2006, she had a percutaneous kidney biopsy.

At the time of the kidney biopsy, physical findings included slim build, blood pressure of $95 / 60 \mathrm{mmHg}$, radial skin folding around the mouth, impaired facial muscle mobility and joint fullness without tenderness or limitation of 


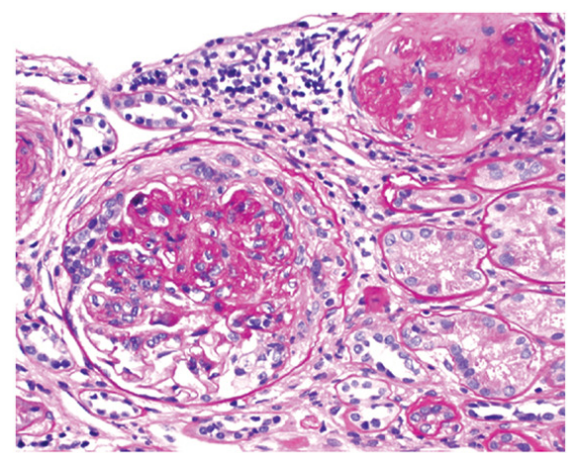

a

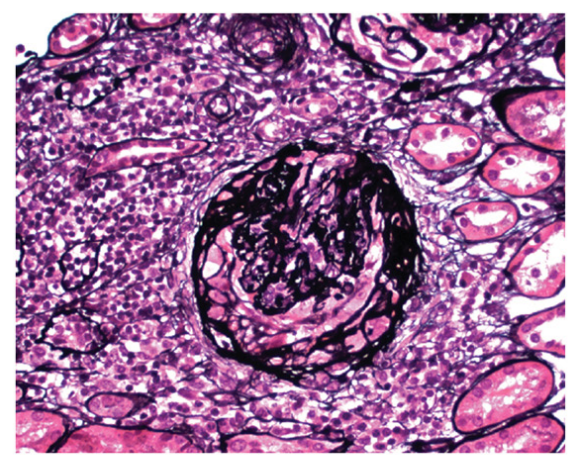

$\mathrm{C}$

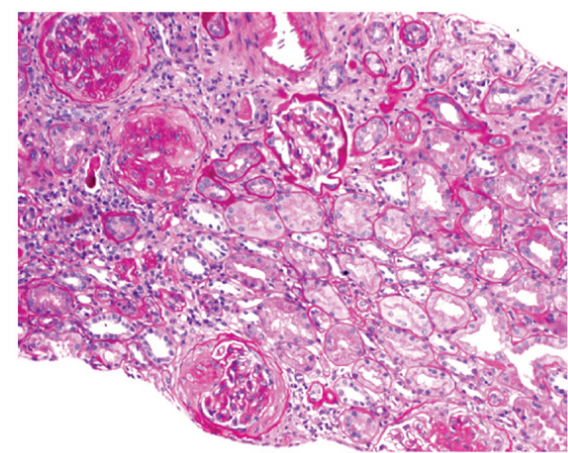

b

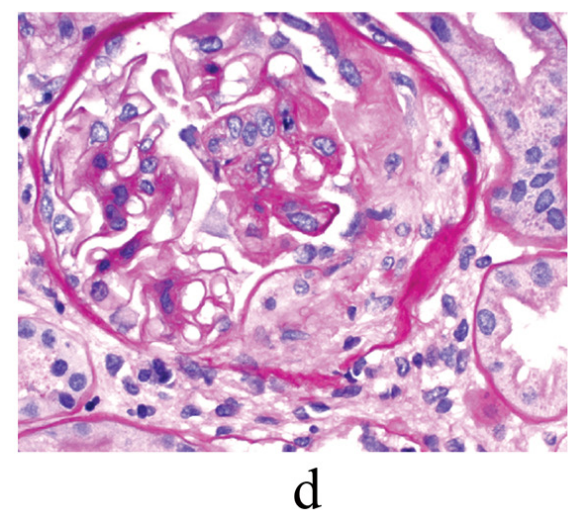

Figure 1. Renal Biopsy findings: Light Microscopy (LM). Focal Proliferative and sclerosing glomerulonephritis with ten percent fibrous crescents, a) Glomerulus with fibro-cellular crescent and one globally sclerotic glomerulus - 200 ×; b) Globally and segmentally sclerosed glomeruli - 40 ×; c) Jones' stain- glomerulus with fibro-cellular crescent $200 \times$; d) Glomerulus with fibro-cellular crescent and some segmental proliferation- $400 \times$.

movement. Edema was absent and the rest of the clinical examination was unremarkable. Laboratory values included erythrocyte sedimentation rate $95 \mathrm{~mm} / \mathrm{hr}$; blood hematocrit $36 \mathrm{vol} \%$, hemoglobin $12 \mathrm{~g} / \mathrm{dL}$, white blood cells $6.3 \mathrm{~K} / \mathrm{mm}^{3}$ and platelets $272 \mathrm{~K} / \mathrm{mm}^{3}$; serum urea nitrogen $11 \mathrm{mg} / \mathrm{dL}$, creatinine $0.9 \mathrm{mg} / \mathrm{dL}$, and albumin $2.9 \mathrm{~g} / \mathrm{dL}$; and urine microscopy with 3 white cells and 140 red cells per high power field. No paraprotein was found in serum or urine electrophoresis.

Renal biopsy revealed focal proliferative and sclerosing glomerulonephritis with ten percent fibrocellular crescents (light microscopy) (Fig. 1, a-d) Immunofluoressence showed scanty mesangial IgG staining and prominent granular IgG staining in the interstitium. Electron microscopy revealed rare sub-epithelial deposits and scattered mesangial deposits (Fig. 2). The histological diagnosis was pauci-immune glomerulonephritis with rare mesangial immune deposits indicative of superimposed immune-complex deposition.

She was treated with monthly intravenous cyclophosphamide $\left(750 \mathrm{mg} / \mathrm{m}^{2}\right)$ for 12 months and tapering dose of oral prednisone. Table 1 shows the evolution of the laboratory values. Statistical comparisons between the four periods of care shown in this table were performed by computing the $95 \%$ confidence intervals of each parameter. Serum ANA

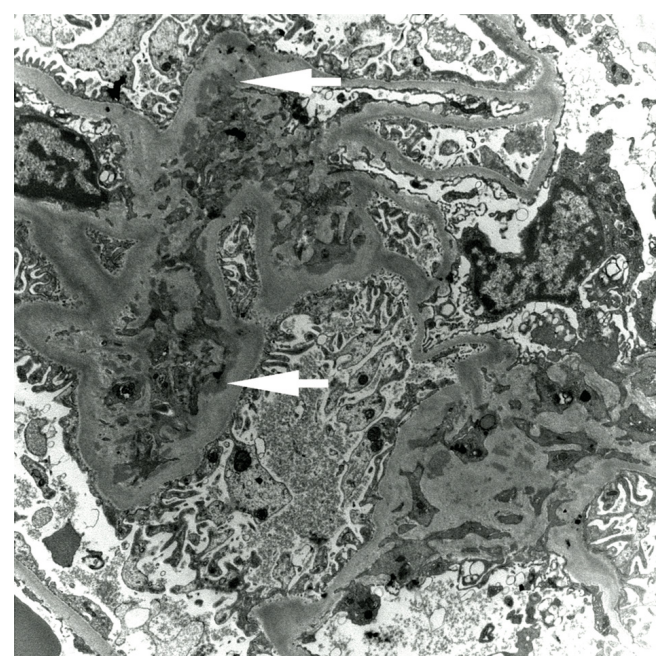

Figure 2. Electron Micrograph (EM). Scattered mesangial immune complex electron dense deposits (marked with white arrows), rare sub-epithelial deposit. 


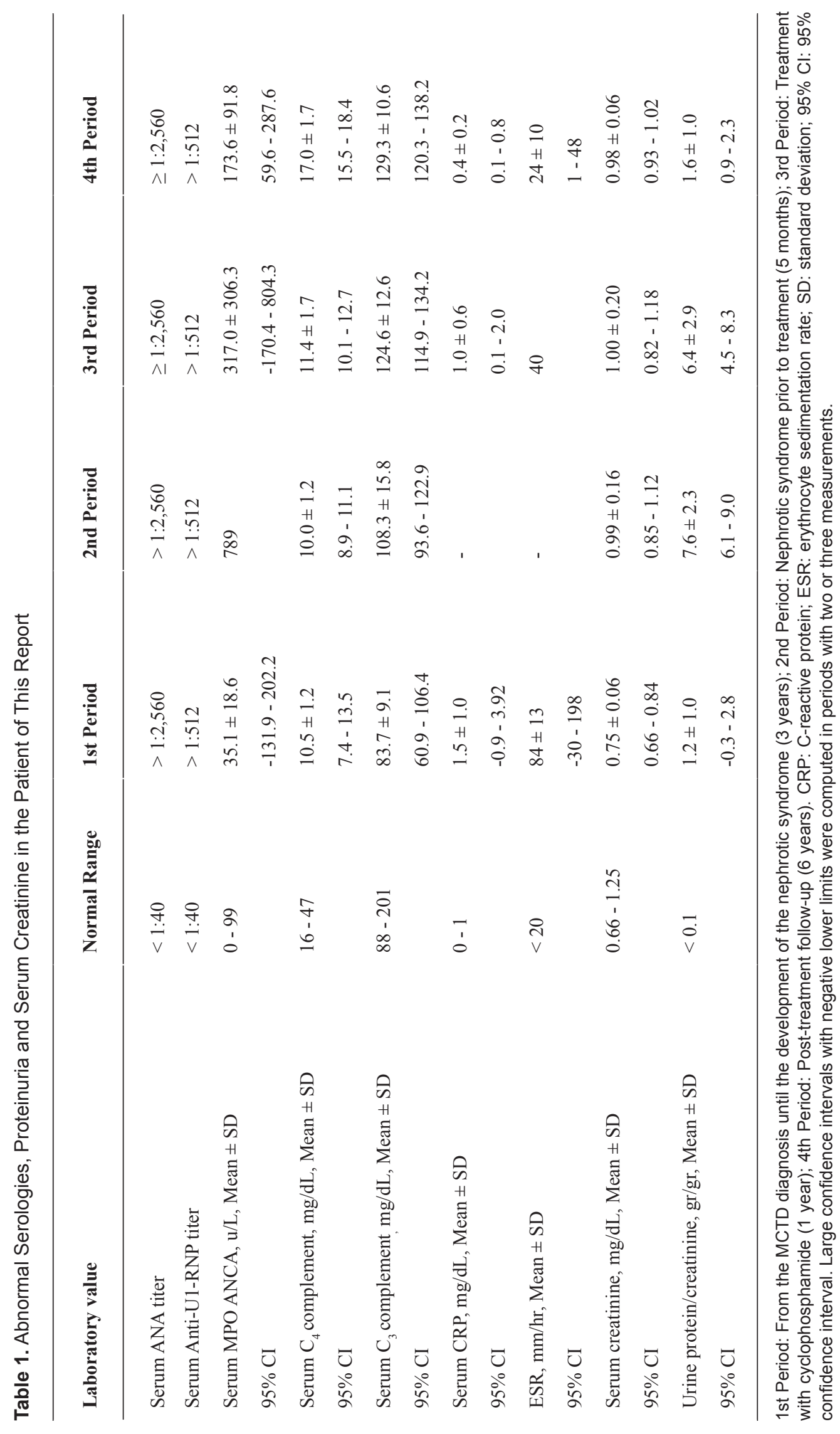




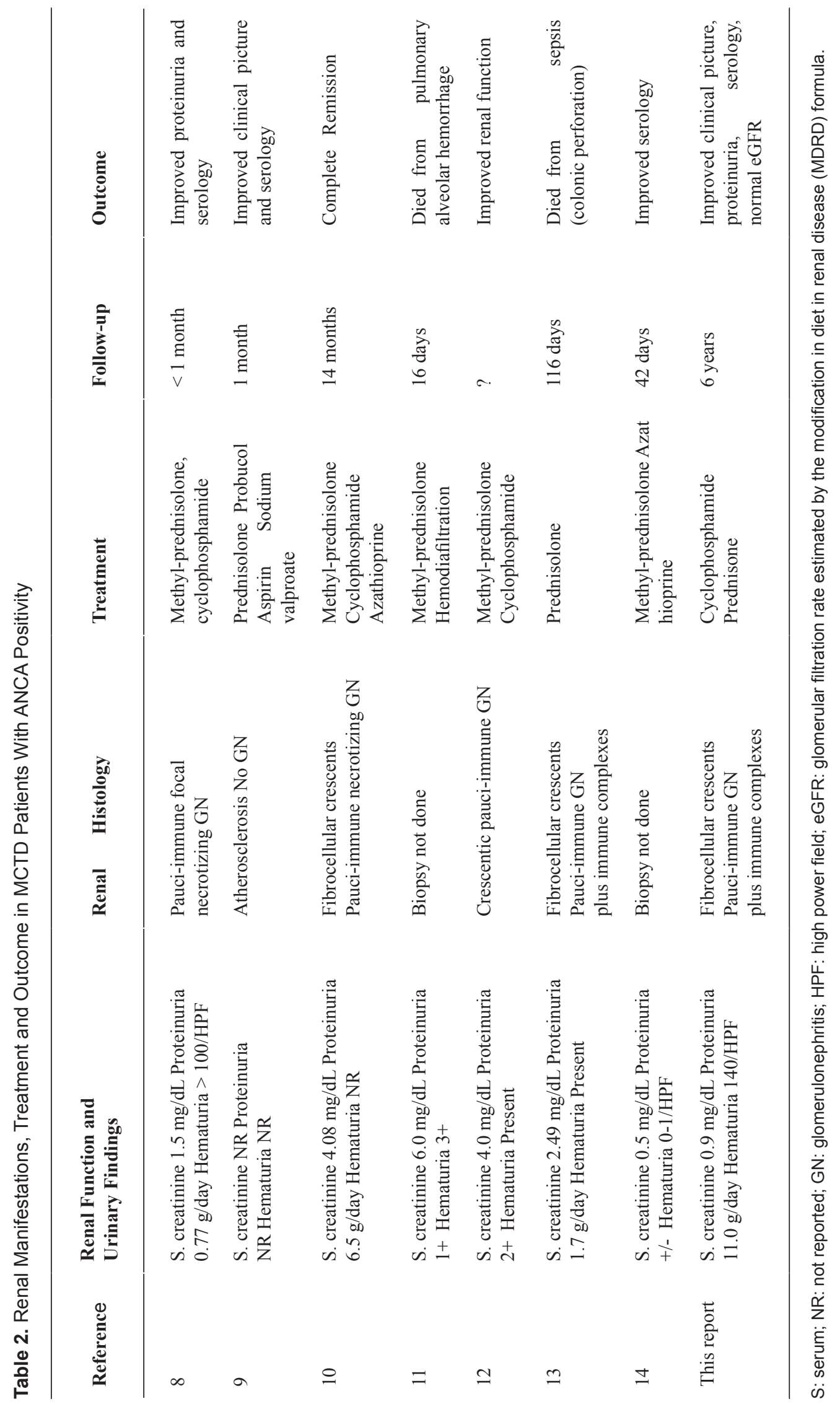


and anti-U1-RNP titers have remained elevated throughout. Serum MPO antibody decreased after treatment. Its last two measurements were within the normal range. $\mathrm{C}_{4}$ serum complement levels were below normal in the pre-treatment and treatment periods and increased to normal levels in the posttreatment period.

The most important findings of Table 1 are those of renal function. Serum creatinine rose slightly after development of nephrotic syndrome, but has not changed in the past seven years. Its last measurement was $0.9 \mathrm{mg} / \mathrm{dL}$ (estimated glomerular filtration rate $>60 \mathrm{~mL} / \mathrm{min}$ ). Proteinuria has returned to its baseline levels. In her last clinic visit, urine protein-to-creatinine ratio was $0.4 \mathrm{gr} / \mathrm{gr}$, serum albumin was $3.9 \mathrm{~g} / \mathrm{dL}$ and hematuria had disappeared. She is maintained on mycophenolate $500 \mathrm{mg}$ twice daily and lisinopril. She has minimal complaints.

\section{Discussion}

The main features of this case presentation are the sustained remission of the renal disease after biopsy-guided treatment and the finding in the renal biopsy of features suggesting superimposition of immune complex-mediated disease on pauci-immune glomerulonephritis. Development of ANCA positivity during the course of MCTD, although rare, is important because it raises the question whether ANCA-associated pathology requiring additional therapeutic interventions has also developed. Biopsy of a clinically involved organ is required to confirm the diagnosis of ANCA-associated disease because MCTD is often the cause of different types of pathology, treated potentially by different medications, in the same organs. The kidneys are one of the target organs of ANCA-associated pathology. The common forms of renal involvement in MCTD are immune complex mediated (membranous nephropathy, membranoproliferative glomerulonephritis).

We found another seven published reports of ANCA formation and evidence of renal disease in patients with MCTD [8-14]. Including the patient of this report, all eight patients were women. Age at diagnosis of ANCA positivity varied between 38 and 68 years. Six patients had MPO-ANCA [8, 10-13] (this report), one had PR3-ANCA [9], and one patient had both MPO and PR3-ANCA [14]. These patients exhibited various patterns of other autoantibodies. Serum complement levels, not reported in two patients $[9,10]$, were depressed in three $[11,13]$ (this report) and normal in the remaining three patients $[8,12,14]$.

Table 2 shows renal manifestations, treatment and outcome of MCTD patients with ANCA positivity. Proteinuria and hematuria were universal. Serum creatinine, not reported in one patient [9], was normal in two [14] (this report) and elevated in the remaining five patients $[8,10-13]$. Renal histology was not available in two patients [11,14]. Among the remaining six patients, one had atherosclerosis of the renal arteries but no glomerulonephritis [9] and the other five patients had pauci-immune glomerulonephritis $[8,10,12,13]$ (this report). Vasculitis treatment (cyclophosphamide and methylprednisolone) was used for patients with pauci-immune glomerulonephritis, while the patient with atherosclerosis received lipid-lowering treatment. Two patients died during hospitalization, one from pulmonary hemorrhage and one from sepsis. Clinical, renal and serological features of the remaining patients improved with treatment.

Follow-up of the other patients in Table 2 was short-term. Only one patient had a follow-up, at 14 months, longer than one year [10]. The sustained improvement of clinical picture, proteinuria and serologies after treatment of vasculitis in our patient, while her renal function remains within the normal range in six years of follow-up, provides evidence that treatment directed against documented ANCA-associated disease can produce long-term benefits in patients with MCTD.

Superimposition of immune complex deposition on ANCA-associated glomerulonephritis was the second important feature of our patient. Presences of small amounts of immunoglobulin in the mesangium and immune complex deposition on the electron microscopic picture were also documented in another MCTD patient diagnosed with pauci-immune glomerulonephritis [13]. The concept of "dual glomerulopathy" is based on the observation of histological features of pauci-immune glomerulonephritis combined with immune complex deposition the magnitude of which cannot explain the extent of the renal histological damage [15]. Superimposition of immune complexes was found in 54\% of 126 cases with pauci-immune glomerulonephritis. Clinical findings suggested that the immune complex deposition worsened the severity of the renal lesion [15].

The superimposition of immune complex deposition on ANCA-associated renal disease in our patient could be the cause of two features that are uncommon in pauci-immune glomerulonephritis, low serum complement levels and nephrotic proteinuria. Serum complement levels were low in only three patients of Table 2 . Our patient and the other patient with dual glomerulopathy [13] had low serum complement, while renal histology was not available in the other patient with hypocomplementemia [11]. Superimposition of immune complex deposition worsens the proteinuria in patients with pauci-immune glomerulonephritis [16]. Global and/or segmental glomerular sclerosis, another feature of our patient's biopsy (Fig. 1), is also associated with nephrotic proteinuria [17]. Nephrotic syndrome is common in MCTD with membranous nephropathy [2], but not in pauci-immune glomerulonephritis. Nephrotic proteinuria was noticed in another patient of Table 2 [10]. After treatment of ANCAassociated disease, complete remission of the nephrotic syndrome was noted in the other patient [10], while our patient had in incomplete, but sustained, remission.

The development of ANCA positivity in patients with 
MCTD should trigger a systematic search for clinical manifestations of ANCA-mediated disease. These manifestations should guide biopsies of involved organs. Proteinuria, abnormal urine sediment and rise in serum creatinine are indications for kidney biopsy. Treatment directed towards ANCAassociated disease should be instituted if the renal biopsy confirms this diagnosis. Sustained remission may follow.

\section{References}

1. Venables PJ. Mixed connective tissue disease. Lupus. 2006;15(3):132-137.

2. Kitridou RC, Akmal M, Turkel SB, Ehresmann GR, Quismorio FP, Jr., Massry SG. Renal involvement in mixed connective tissue disease: a longitudinal clinicopathologic study. Semin Arthritis Rheum. 1986;16(2):135145.

3. Michels H. Course of mixed connective tissue disease in children. Ann Med. 1997;29(5):359-364.

4. Bennett RM, Spargo BH. Immune complex nephropathy in mixed connective tissue disease. Am J Med. 1977;63(4):534-541.

5. Kobayashi S, Nagase M, Kimura M, Ohyama K, Ikeya M, Honda N. Renal involvement in mixed connective tissue disease. Report of 5 cases. Am J Nephrol. 1985;5(4):282-289.

6. Ito S, Nakamura T, Kurosawa R, Miyamae T, Imagawa T, Mori M, Aihara Y, et al. Glomerulonephritis in children with mixed connective tissue disease. Clin Nephrol. 2006;66(3):160-165.

7. Yamaguchi T, Ohshima S, Tanaka T, Tsukada S, Matsushita M, Kohmo S, Kanzaki T, et al. Renal crisis due to intimal hyperplasia in a patient with mixed connective tissue disease (MCTD) accompanied by pulmonary hypertension. Intern Med. 2001;40(12):1250-1253.

8. Makita N, Katori H, Takemoto F, Yokota M, Kitamura Y, Ubara Y, Hara S, et al. A case of mixed connective tissue disease (MCTD) complicated with MPO-ANCA- related necrotizing glomerulonephritis. Clin Nephrol. 2000;54(2):164-168.

9. Kanazawa M, Wada Y, Ohno T, In H, Yahata K, Izumi J, Tanaka H, et al. Mixed connective tissue disease associated with antineutrophil cytoplasmic antibodies against proteinase-3 and systemic atherosclerosis: a case report. Clin Rheumatol. 2004;23(5):456-459.

10. Hernandez-Molina G, Reyes E, Crispin JC. ANCA associated glomerulonephritis in a patient with mixed connective tissue disease. Ann Rheum Dis. 2006;65(3):410411.

11. Kitaura K, Miyagawa T, Asano K, Oouchi S, Miki T, Fujisawa T, Ishida K. Mixed connective tissue disease associated with MPO-ANCA-positive polyangiitis. Intern Med. 2006;45(20):1177-1182.

12. Hong HS, Park JH, Lee JH, Yi JH, Han SW, Park MH, Kim HJ. MPO-ANCA associated rapidly progressive glomerulonephritis in a patient with mixed connective tissue disease. Korean J Nephrol 2010; 29:6776-781.

13. Murakami T, Endo S, Moriki T, Doi T, Matsumoto $\mathrm{Y}$. Mixed connective tissue disease developing into MPO-ANCA-positive polyangiitis. Intern Med. 2011;50(6):591-595.

14. Murakami M, Shimane K, Takahashi H, Tomiyama J, Nagashima M. ANCA-associated vasculitis with dual ANCA positivity in coexistence with mixed connective tissue disease. Mod Rheumatol. 2013;23(1):156-161.

15. Haas M, Eustace JA. Immune complex deposits in ANCA-associated crescentic glomerulonephritis: a study of 126 cases. Kidney Int. 2004;65(6):2145-2152.

16. Neumann I, Regele H, Kain R, Birck R, Meisl FT. Glomerular immune deposits are associated with increased proteinuria in patients with ANCA-associated crescentic nephritis. Nephrol Dial Transplant. 2003;18(3):524-531.

17. Mollet G, Ratelade J, Boyer O, Muda AO, Morisset L, Lavin TA, Kitzis D, et al. Podocin inactivation in mature kidneys causes focal segmental glomerulosclerosis and nephrotic syndrome. J Am Soc Nephrol. 2009;20(10):2181-2189. 